\title{
Очистка сточных вод 000 «Ловозерский ГОК» от ионов фтора методом химической коагуляции
}

Красавцева Е.А. ${ }^{1,2}$, Жилкин Б.О. ${ }^{3}$, Макаров Д.В. ${ }^{1}$, Светлов А.В. ${ }^{1}$, Горячев А.А. ${ }^{1,2}$

${ }^{1}$ ИППЭС ФИЦ КНЦ РАН, Anamumbl,mdv_2008@mail.ru, antonsvetlov@mail.ru

2ЛПТиТБА ФИЦКНЦ РАН, Anamumb, e.krasavtseva@ksc.ru, a.goryachev@ksc.ru

${ }^{3}$ АФ МГТУ, Anamumbl, b_zhilkin@mail.ru

Аннотация. Очистка сточных вод горнодобывающих предприятий остаётся актуальной проблемой на протяжении многих лет. В данной работе рассмотрена возможность очистки сточных вод рудника «Карнасурт» ООО «Ловозерский ГОК» от ионов фтора методом химической коагуляции. Эксперименты проводились как на модельных растворах, так и на сточной воде, отобранной из выпуска предприятия в реку Сергевань. Удалось добиться снижения концентрации фторид-ионов до уровня ПДК, вместе с тем необходимо искать пути оптимизации расхода реагентов.

Ключевые слова: горно-обогатительный комбинат, шахтные воды, методы очистки сточных вод, загрязняющие вещества, ионы фтора, предельно допустимая концентрация (ПДК).

\section{Wastewater treatment of the Lovozersky GOK LLC from fluorine ions by chemical coagulation}

\author{
Krasavtseva E.A. ${ }^{1,2}$, Zhilkin B.O. ${ }^{3}$, Makarov D.V. ${ }^{1}$, Svetlov A.V. ${ }^{1}$, Goryachev A.A. ${ }^{1,2}$ \\ ${ }^{1}$ Institute of North Industrial Ecology Problems of FRC KSC RAS, Apatity,mdv_2008@mail.ru, \\ antonsvetlov@mail.ru \\ ${ }^{2}$ Laboratory of Nature-Inspired Technologies and Environmental Safety of the Arctic of FRC KSC RAS, \\ Apatity,e.krasavtseva@ksc.ru,a.goryachev@ksc.ru \\ 33ABMSTU, Apatity,b_zhilkin@mail.ru
}

\begin{abstract}
Mining enterprises wastewater treatment has been a significant problem for many years. In this paper, a possibility of the fluorine ions removal from the Karnasurt mine wastewater (Lovozersky GOK LLC) by chemical coagulation was considered. The experiments were carried out both on model solutions and on wastewater taken from the enterprise discharge into the Sergevan river. It was possible to achieve a decrease in the concentration of fluoride ions to the MPC level, however, it is necessary to find ways to optimize the reagents consumption.
\end{abstract}

Key words: mining and processing plant, mine water, wastewater treatment methods, pollutants, fluoride ions, maximum permissible concentration (MPC).

\section{Введение}

В настоящее время проблема обезвреживания и очистки сточных вод является одной из наиболее значимых и отражена во многих федеральных программах РФ. Важнейшее направление экологизации современного производства - разработка и внедрение технологически эффективных и экономически обоснованных способов очистки сточных вод (Дударев и др., 2014).

В Мурманской области сосредоточены несколько крупных горнодобывающих предприятий, в результате деятельности которых образуются сточные воды с повышенным содержанием различных загрязняющих веществ, в том числе - фтора. В настоящее время очистка стоков остаётся актуальной проблемой, поскольку зачастую они сбрасываются в водоёмы культурно-бытового (ПДК хпкб $=1.5$ мг/л) и рыбохозяйственного назначения (ПДК сле недостаточной очистки.

В работе рассматриваются сточные воды рудника «Карнасурт» (ООО «Ловозерский ГОК»), расположенного в центре Мурманской области в нескольких километрах южнее поселка Ревда. На данный момент очистка стоков производится в два этапа. На первом - за счет гравитационного осаждения взвесей в шахтных выработках, которые выведены из эксплуатации. Предприятием выполнен анализ притока дренажных вод. Установлено, что часть вод рудника представлена услов- 
но чистыми дренажными водами, имеющими первичное загрязнение, сопоставимое с требованиями ПДК рбх Выполнено разделение вод на условно чистые, и воды из зоны активных выработок. Последние необходимо отстаивать, в том числе и с применением химической коагуляции, для интенсификации процесса. Перед вторым этапом осаждения шахтные воды снова объединяются и организованно, последовательно, направляются в два прудка-отстойника уже на поверхности. После итогового отстаивания очищенные воды направляются в реку Сергевань, являющуюся притоком первого порядка озера Ловозеро, которое имеет высшую категорию водоема рыбохозяйственного назначения.

Повышенное содержание ионов фтора в сточных водах предприятия объясняется лёгкой растворимостью виллиомита (фторида натрия) - минерала, входящего в состав пород рудника.

Фтор является одним из опасных химических веществ, которые, как известно, вызывают крупномасштабные проблемы со здоровьем при употреблении питьевой воды (Ауоob, 2006; Maiti et al., 2011).

Известны и достаточно широко применяются на практике различные способы очистки сточных вод предприятий от фтора: химическое осаждение и коагуляция, ионный обмен, электрокоагуляция и мембранные процессы - у каждого из них есть свои преимущества и недостатки.

Удаление фтора из воды может быть достигнуто различными физико-химическими и биологическими методами, однако одни только биологические методы могут быть неэффективными, лучший результат достигается при комплексном подходе (Mekonen, 2001). Было показано, что адсорбционное удаление фтора является эффективной стратегией (Liu et al., 2010; Tripathy et al., 2006). Хотя активированный уголь, полученный из различных ресурсов биомассы, традиционно использовался в качестве адсорбента для удаления фтора, необходимы исследования, чтобы найти альтернативные адсорбенты, такие как глинистые минералы, которые являются природными, возобновляемыми и экологически устойчивыми (Bergaya, 2013; Srinivasan, 2011). Из-за своей низкой стоимости, высоких сорбционных свойств и потенциала ионного обмена глинистые материалы считаются надежными адсорбентами (Crini, 2006). Реагентная очистка сточных вод уже была недавно рассмотрена в работах (Беликов и др., 2018; Макаров и др., 2019).

В данном случае для обесфторивания растворов использовался метод коагуляции в сочетании с флокуляцией. Коагуляция в традиционном или модифицированном исполнении - это эффективный способ очистки сточных вод от примесей, находящихся в мелкодисперсном или эмульгированном состоянии.

Затраты на реализацию метода невелики, они могут существенно уменьшаться при использовании недорогих реагентов, а в лучшем случае - отходов или побочных продуктов производств.

\section{Объекты и методы исследования}

В качестве объектов исследования выступали модельные растворы с разным содержанием ионов фтора (10 и 100 мг/л), шахтная вода (10.85 мг/л фтор-ионов), отобранная с выпуска на реку Сергевань из рудника «Карнасурт».

Рассмотрены следующие реагенты: флокулянты - «Магнафлок 333», «Праестол 2515»; коагулянты - полиоксихлорид алюминия («Аква-Аурат-30»), хлорид железа $\left(\mathrm{FeCl}_{3}\right)$.

Измерение рН осуществляли с помощью иономера И-160-МИ. Определение концентрации фтор-ионов в воде проводили потенциометрическим методом с использованием электродной системы, состоящей из фторидного ионселективного электрода ЭЛИС-131F и вспомогательного хлорсеребряного электрода Эср-10103. Остаточное содержание ионов хлора, алюминия и железа определяли по методикам ПНД Ф 14.1:2:4.157-99, ПНД Ф 14.1:2:4.139-98. Метод капиллярного электрофореза для определения массовой концентрации неорганических анионов основан на их миграции и разделении под действием электрического поля вследствие их различной электрофоретической подвижности. Идентификацию и количественное определение анализируемых анионов проводят косвенным методом, регистрируя ультрафиолетовое поглощение на длине волны 254 нм («Капель-103Р/103РТ/104/104T/104М») или 374 нм («Капель-105/105М»), используя в качестве ве- 
дущего электролита хроматный буферный раствор. Метод атомно-абсорбционной спектрометрии основан на измерении резонансного поглощения света свободными атомами определяемого металла при прохождении света через атомный пар исследуемого образца, образующийся в пламени.

\section{Результаты}

На начальном этапе эксперименты проводились на модельных фторсодержащих растворах фторида натрия $(10,100$ мг/л F-). Варьировали вид и расход коагулянта от 50 до 150 мг/л, вид флокулянта, время взаимодействия составляло 30 мин. Результаты представлены в таблице 1.

Анализ полученных результатов показал целесообразность использования в качестве коагулянта для дальнейших экспериментов с шахтной водой полиоксихлорида алюминия (Аква-Аурат 30). Вероятно, недостаточная степень обесфторивания модельных растворов хлорным железом объясняется сильным снижением рН растворов (Савельев и др., 2018). Остаточные концентрации железа, алюминия и хлор-ионов не превышают предельно допустимых значений.

Таблица 1. Коагуляционная очистка модельных растворов от фтора.

Table 1. Coagulation treatment of model solutions from fluorine.

\begin{tabular}{|c|c|c|c|c|c|c|c|c|c|c|c|c|}
\hline \multicolumn{13}{|c|}{ Модельный раствор фторида натрия, 10 мг/л по фтору } \\
\hline Вид флокулянта & \multicolumn{6}{|c|}{ Праестол 2515} & \multicolumn{6}{|c|}{ Магнафлок 333} \\
\hline Вид коагулянта & \multicolumn{3}{|c|}{ Аква-Аурат 30} & \multicolumn{3}{|c|}{ Хлорид железа } & \multicolumn{3}{|c|}{ Аква-Аурат 30} & \multicolumn{3}{|c|}{ Хлорид железа } \\
\hline Расход коагулянта, мг/л & 50 & 100 & 150 & 50 & 100 & 150 & 50 & 100 & 150 & 50 & 100 & 150 \\
\hline $\mathrm{C}_{\mathrm{F}}{ }_{\text {кон. }}, \mathrm{MГ} /$ Л & 2.99 & 1.4 & 0.6 & 8.81 & 8.46 & 7.72 & 2.60 & 0.92 & 0.25 & 9.25 & 7.73 & 6.6 \\
\hline $\mathrm{pH}_{\text {кон. }}$ & 6.15 & 5.57 & 5.13 & 3.89 & 3.51 & 3.33 & 5.44 & 5.46 & 5.19 & 3.40 & 3.13 & 3.07 \\
\hline \multicolumn{13}{|c|}{ Модельный раствор фторида натрия, 100 мг/л по фтору } \\
\hline Вид флокулянта & \multicolumn{6}{|c|}{ Праестол 2515} & \multicolumn{6}{|c|}{ Магнафлок 333} \\
\hline Вид коагулянта & \multicolumn{3}{|c|}{ Аква-Аурат 30} & \multicolumn{3}{|c|}{ Хлорид железа } & \multicolumn{3}{|c|}{ Аква-Аурат 30} & \multicolumn{3}{|c|}{ Хлорид железа } \\
\hline Расход коагулянта, мг/л & 50 & 100 & 150 & 50 & 100 & 150 & 50 & 100 & 150 & 50 & 100 & 150 \\
\hline $\mathrm{C}_{\mathrm{F}}{ }_{\text {кон. }}, \mathrm{MГ} / л$ & 77.3 & 68 & 59.8 & 83.8 & 77.5 & 70.3 & 77.9 & 67.0 & 45.1 & 84.1 & 75.1 & 67.2 \\
\hline $\mathrm{pH}_{\text {кон. }}$ & 6.71 & 6.92 & 6.73 & 4.88 & 4.66 & 4.48 & 6.27 & 6.39 & 6.22 & 4.59 & 4.27 & 3.98 \\
\hline
\end{tabular}

Представляло интерес изучить влияние температуры на эффективность очистки стоков. Поэтому провели две серии экспериментов с шахтной водой комнатной температуры и предварительно охлаждённой до $4{ }^{\circ} \mathrm{C}$. Результаты представлены в таблице 2.

Таблица 2. Коагуляционная очистка шахтных вод рудника Карнасурт от фтора.

Table 2. Coagulation treatment of mine water of the Karnasurt mine from fluorine.

\begin{tabular}{|c|c|c|c|c|c|c|}
\hline \multicolumn{7}{|c|}{ Шахтная вода комнатной температуры } \\
\hline Вид флокулянта & \multicolumn{3}{|c|}{ Праестол 2515} & \multicolumn{3}{|c|}{ Магнафлок 333} \\
\hline Расход коагулянта, мг/л & 50 & 100 & 150 & 50 & 100 & 150 \\
\hline $\mathrm{C}_{\mathrm{F}^{-}}{ }_{\text {кон. }}, \mathrm{M \Gamma} /$ л & 4.15 & 2.75 & 1.34 & 4.38 & 3.52 & 2.12 \\
\hline $\mathrm{pH}_{\text {кон. }}$ & 6.62 & 6.39 & 5.74 & 6.62 & 6.39 & 5.74 \\
\hline \multicolumn{7}{|c|}{ Шахтная вода, охлаждённая до $4^{\circ} \mathrm{C}$} \\
\hline Вид флокулянта & \multicolumn{3}{|c|}{ Праестол 2515} & \multicolumn{3}{|c|}{ Магнафлок 333} \\
\hline Расход коагулянта, мг/л & 50 & 100 & 150 & 50 & 100 & 150 \\
\hline $\mathrm{C}_{\mathrm{F}^{-} \text {кон. }}, \mathrm{M \Gamma} /$ Л & 5.89 & 3.5 & 1.67 & 6.09 & 3.39 & 1.7 \\
\hline $\mathrm{pH}_{\text {кон. }}$ & 7.01 & 6.44 & 5.73 & 7.12 & 6.65 & 6.38 \\
\hline
\end{tabular}


Опыты с использованием флокулянта и коагулянта продемонстрировали возможность использования метода коагуляции для очистки воды от ионов фтора. В некоторых случаях удалось добиться снижения концентрации фтор-ионов в воде до уровня ПДК (1.5 мг/л для питьевой воды). Влияние температуры минимально.

К минусам метода можно отнести большой расход реагентов, необходимость разработки схем утилизации осадков.

Рассматривается схема разделения сточных шахтных вод рудника «Карнасурт» для сокращения объемов загрязненных рудничных вод и повышения в них концентраций загрязнителя, что повысит эффективность извлечения фтор-ионов известными и отработанными методами, а очистка условно грязной воды до ПДК не потребуется (Красавцева и др., 2019).

\section{Заключение}

Наиболее перспективными направлениями очистки воды от фтора для вод горнорудных предприятий представляются комбинированные технологии, позволяющие с высокой эффективностью и необратимо удалять фтор в широком диапазоне концентраций, включающие химическое осаждение, коагуляцию и сорбционные процессы.

Для высоких исходных концентраций фтора порядка 100 мг/л эффективны технологии химического осаждения, коагулянты и флокулянты, ввиду достаточно высокой стоимости, можно использовать для менее концентрированных растворов. На стадии предварительной очистки можно применять известь, магнезит и другие $\mathrm{Ca}, \mathrm{Mg}$ содержащие реагенты, получаемые из отходов местных горнодобывающих предприятий (карбонатит, брусит и т.д.). Для дальнейшего снижения концентрации ионов фтора возможно использование коагулянта полиоксихлорида алюминия в сочетании с флокулянтами «Праестол 2515» и «Магнафлок 333» с целью интенсификации процесса коагулирования, при малом расходе которых вторичного загрязнения стоков не произойдёт.

Важно отметить, что реализуемая на предприятии схема отвода поступающих в рудник дренажных вод (условно чистых), за счет перехвата до смешения с загрязненными водами в выработках, позволяет значительно снизить объемы очищаемых вод. В этом случае появится возможность проведения очистки в отработанных пространствах рудника известными и отработанными методами. Необходимо, учитывая водный баланс рудника, производить снижение концентраций фтора до тех значений, что при смешении с условно чистой дренажной водой будут давать значения безопасные для окружающей среды.

Работа выполнена в рамках тем НИР №№ 9-18-2514, 0226-2019-0011 и частично поддержана из средств гранта РФФИ (проект №18-05-60142 Арктика).

\section{Литература}

1. Беликов М.Л. Локшин Э.П. Очистка сточных вод от фтора соединениями железа и алюминия // Цветные металлы. 2018. № 1. С. 39-43.

2. Дударев В.И., Баранов А.Н., Филатова Е.Г., Минаева Л.А. Деманганация сточных вод электрохимическим способом // Вестник ИрГТУ. 2014. № 4. (87). С. 124-127.

3. Красавцева Е.А., Светлов А.В., Горячев А.А., Макаров Д.В., Маслобоев В.А. Очистка сточных вод от фтора // Сб. материалов междун. совещания «Проблемы и перспективы эффективной переработки минерального сырья в ХХ веке (Плаксинские чтения - 2019)». 2019. С. 402-405.

4. ПНД Ф 14.1:2:4.157-99. Количественный химический анализ вод. Методика выполнения измерений массовых концентраций хлорид-ионов, нитрит-ионов, сульфат-ионов, нитрат-ионов, фторид-ионов и фосфат-ионов в пробах природных, питьевых и очищенных сточных вод с применением системы капиллярного электрофореза «Капель».

5. ПНД Ф 14.1:2:4.139-98. Количественный химический анализ вод. Методика измерений массовых концентраций кобальта, никеля, меди, цинка, хрома, марганца, железа, серебра, кадмия и свинца в пробах питьевых, природных и сточных вод методом атомно-абсорбционной спектрометрии.

6. Савельев С.Н., Савельева А.В., Фридланд С.В. Исследование коагуляционно-флокуляционной очистки сточной воды производства органического синтеза // Вестник технологического университета. 2018. T. 21. № 1. 173c. 
7. Ayoob S., Gupta A.K. Fluoride in drinking water: a review on the status and stress effects // Critical reviews in environmental science and technology. 2006. 36. P. 433-487. http://dx.doi.org/10.1080/ 10643380600678112.

8. Bergaya F., Lagaly G. General introduction: clays, clay minerals, and clay science // Developments in Clay Science. 2013. 5. P. 1-19. http://dx.doi.org/10.1016/B978-0-08-098258-8.00001-8.

9. Crini G. Non-conventional low-cost adsorbents for dye removal: a review // Bioresource Technology. 2006. 97. P. 1061-1085. http://dx.doi.org/10.1016/j.biortech.2005.05.001.

10. Liu H., Deng S., Li Z., Yu G., Huang J. Preparation of Al-Ce hybrid adsorbent and its application for defluoridation of drinking water // Journal of Hazardous Materials. 2010. 179. P. 424-430. http://dx.doi.org/10.1016/j. jhazmat.2010.03.021.

11. Maiti A., Basu J.K., De S. Chemical treated laterite as promising fluoride adsorbent for aqueous system and kinetic modeling // Desalination. 2011. 265. P. 28-36. http://dx.doi.org/ 10.1016/j.desal.2010.07.026.

12. Makarov D.V., Svetlov A.V., Goryachev A.A., Masloboev V.A., Minenko V.G., Samusev A.L., Krasavtseva E.A. Mine waters of the mining enterprises of the murmansk region: main pollutants, perspective treatment technologies // Mine Water: Technological and Ecological Challenges Proceedings of International Mine Water Association Conference. 2019. P. 206-211.

13. Mekonen A. Integrated biological and physiochemical treatment process for nitrate and fluoride removal // Water Research. 2001. 35. P. 3127-3136. http://dx.doi.org/10.1016/ S0043-1354(01)00019-7.

14. Srinivasan R. Advances in application of natural clay and its composites in removal of biological, organic, and inorganic contaminants from drinking water // Advances in Materials Science and Engineering. 2011. 1. 17. http://dx.doi.org/10.1155/2011/872531.

15. Tripathy S.S., Bersillon J.L., Gopal K. Removal of fluoride from drinking water by adsorption onto alumimpregnated activated alumina // Separation and Purification Technology. 2006. 50. P. 310-317. http://dx.doi. org/10.1016/j.seppur.2005.11.036. 